\title{
VISÃO DOS BANHISTAS E COMERCIANTES SOBRE O CENÁRIO AMBIENTAL DA PRAIA DE PONTA NEGRA, NATAL-RN
}

\begin{abstract}
Jairo Rodrigues Souza
jairo.souza@ifrn.edu.br

Lana Machado Alves

Alder Pereira Fontenelle Filho

Carmem Sara Pinheiro Oliveira

Maria Gabriella Pinheiro

https://doi.org/10.15628/geoconexoes.2019.9196

\section{RESUMO}

O objetivo deste artigo foi apresentar a visão dos banhistas e comerciantes sobre o cenário ambiental da praia de Ponta Negra. A metodologia empregada utilizou-se de uma abordagem dialética que buscou a transformação da realidade atual por meio de investigação e atuação direta. Foram realizadas coletas in loco para acompanhamento dos hábitos de comerciantes do entorno, comunidade local e banhistas. Foram utilizadas conversas informais com os sujeitos que usufruíram da região, no qual utilizamos anotações, registros fotográficos e coleta de materiais na faixa da areia. Diante disso, muitos afirmaram que é preciso que haja uma cobrança maior sobre o indivíduo que polui o meio, visando a manutenção de uma praia mais limpa, principalmente sobre aqueles que não possuem o sentimento de responsabilidade diante do ecossistema. Muitos também afirmam que, além da maior exigência de responsabilidade por parte dos civis, é preciso que o poder público também assume o dever de preservar e defender a praia. A partir desses impasses, muitos indivíduos sugeriram que haja mais projetos e programas com a temática de educação ambiental, argumentando sobre a necessidade de maior propagação da importância de uma praia limpa. Concluímos, que é importante ressaltar que a visão dos sujeitos envolvidos no uso constante do recurso natural, sendo de extrema relevância para a compreensão da educação ambiental e do meio ambiente na Praia de Ponta Negra, uma vez que são essenciais na intermediação da relação do ser humano com o meio ambiente.
\end{abstract}

Palavras-chave: Educação, Meio Ambiente, Praia.

\section{ABSTRACT}

The objective of this work was to present the view of bathers and merchants about the environmental scenery of Ponta Negra beach. The methodology used was based on a dialectical approach that sought to transform current reality through research and direct action. In loco collections were carried out to follow the habits of local merchants, local community and bathers. Informal conversations were used with the subjects who enjoyed the region, in which we used annotations, photographic records and 
collection of materials in the sand strip. In view of this, many have stated that it is necessary that there be a greater charge on the individual who pollutes the environment, aiming at maintaining a cleaner beach, especially on those who do not have the sense of responsibility towards the ecosystem. Many also argue that, in addition to the increased demand for civilian accountability, public authorities also have a duty to preserve and defend the beach. From these impasses, many individuals have suggested that there be more projects and programs on the subject of environmental education, arguing about the need to further spread the importance of a clean beach. We conclude that it is important to emphasize that the view of the subjects involved in the constant use of the natural resource, being extremely relevant to the understanding of environmental education and the environment in Ponta Negra Beach, since they are essential in the intermediation of the relationship of being with the environment.

Keywords: Education; Environment; Beach.

\section{INTRODUÇÃO}

As regiões litorâneas, espaço delimitado entre as terras emersas e submersas (SUGUIO, 2003), são comumente encontradas ao redor de grandes cidades e metrópoles, as quais impulsionam a economia local, pois são atrativos turísticos. Assim, há uma forte relação entre o crescimento urbano e sua proximidade ao litoral, visto que é uma grande fonte de renda e lazer (PEREIRA, 2012). Todavia, essa proximidade acaba causando uma superlotação do espaço praial gerando degradação ambiental.

Em Natal, capital do estado do Rio Grande do Norte, os litorais seduzem os turistas e admiradores de todo o planeta, em decorrência das belas praias e esculturas morfológicas em seu entorno. De acordo com Aires (2010), a presença dessas pessoas na cidade contribui na efervescência da capitalização, promovendo também um intercâmbio cultural entre diferentes etnias. A "Cidade do Sol", como é conhecida Natal-RN, tem como principal praia urbana a Ponta Negra, contendo nela o Morro do Careca, maior cartão-postal do município.

O Morro do Careca apresenta 120 metros de altura e exibe uma gigante beleza natural, atraindo diversos turistas diariamente, principalmente na alta estação. Esse grande fluxo de pessoas gera degradação ambiental, em virtude do descarte incorreto de resíduos sólidos (ARAÚJO et al., 2011). Esses resíduos sólidos são um dos grandes problemas encontrados na sociedade natalense, cuja cidade do Natal-RN é a segunda maior geradora de resíduos sólidos do país com cerca de 743 toneladas/dia, sendo 6 toneladas/dia recicláveis, possuindo um sistema falho na disposição final desses resíduos (BISPO, 2013).

A gestão e a disposição inadequada dos resíduos sólidos causam impactos socioambientais, tais como: degradação do solo; comprometimento dos corpos d'água e mananciais; intensificação de enchentes; poluição do ar; proliferação de vetores patogênicos de importância sanitária nos centros urbanos e catação de resíduos em condições insalubres nas ruas e nas áreas de disposição final (BESEN et al., 2010). 
Com o crescimento populacional da sociedade, o consumo rapidamente aumenta, porém, a consciência de cuidar e reciclar (quando possível) deste "lixo" gerado não foi muitas vezes assumida. Isso se caracteriza pela falta de educação ambiental que prejudica o meio em que esses resíduos são depositados, prejudicando a população e desqualificando a ideia de uma reforma urbana ecológica sugerida por Pádua (1987).

O descaso de toda a sociedade com este espaço tão importante para a cidade não vem tendo o devido cuidado sustentável, afastando, assim, a vinda de comuns frequentadores. Sustentabilidade é um tema que diverge opiniões e abrange para muitos conceitos diferentes (BENJAMIN, 1998). Sendo base para a criação da CARTA DA TERRA (1992), o desenvolvimento sustentável se torna critério comum e pode ser brevemente definido como conservação ambiental em respeito à toda forma de vida, tendo os cidadãos e o Estado, responsabilidade civil com a causa independentemente da obrigação de reparar os danos causados, segundo o artigo 225, parágrafos $1^{\circ}$ e $3^{\circ}$ da Constituição Federal (1988) e do artigo 14, parágrafo $1^{\circ}$ da Lei 6.938/1981 - Lei da Política Nacional do Meio Ambiente (1981). Todavia, a aplicação da mesma é de notória relevância no cenário atual.

Diante do exposto, foi criado o projeto de extensão “Ponta Negra: Menos lixo. Mais saúde" realizado pelo Instituto Federal de Educação, Ciência e Tecnologia do Rio Grande do Norte - campus Natal Central (IFRN/Natal Central). Seu objetivo era realizar campanhas semanais de conscientização aos banhistas e aos trabalhadores do local acerca da relevância da correta destinação dos resíduos sólidos. Para tanto, realizaram-se questionários durante um período de cinco meses.

No entanto, no contexto mais vasto acerca do projeto, buscou-se compreender, na prática, em perspectiva da praia de Ponta Negra, a importância da educação ambiental, bem como a consciência ambiental dos usuários do local, principalmente daqueles que possuem esse litoral como um meio de lazer e trabalho. Vale ressaltar que, tendo a perspectiva de Marx (2011), o trabalho é o fator que faz a mediação entre o homem e a natureza, sendo a expressão da vida humana, portanto, através desse, há a transformação do ambiente, alterando-se o homem a si mesmo. Em outras palavras, "o trabalho é uma atividade fundamental do homem, pois mediatiza a satisfação de suas necessidades diante da natureza e de outros homens" (IAMAMOTO, 2001, apud OLIVEIRA; SANTOS; CRUZ, 2007).

Dessa perspectiva acerca do trabalho e do meio ambiente, os trabalhadores, conforme Romão (2004, p. 3 apud CARDOZO; SILVA, 2014, p. 26), possuem a capacidade de transformar sentimentos em realidade e reunir, à sua volta, pessoas com um mesmo objetivo e com visões concretas. Logo, é imprescindível que a perspectiva dos comerciantes da praia de Ponta Negra seja exposta, isto é, a visão deles sobre a relação humano-natureza e educação ambiental.

Portanto, o objetivo deste artigo foi apresentar a visão dos banhistas e comerciantes sobre o cenário ambiental da praia de Ponta Negra, zona sul da cidade de Natal-RN por meio de aplicação de questionários educativos, durante os meses de maio a setembro de 2018. 


\section{MATERIAIS E MÉTODOS}

A área de estudo está situada na praia urbana de Ponta Negra numa extensão de um quilômetro e duzentos e oitenta metros, abrangendo desde o Morro do Careca até a rua da antiga casa de shows Peppers Hall, conforme a figura 01. Ela foi dividida em três subáreas com dimensões de trezentos metros cada, a fim de facilitar a logística e dinamicidade das atividades.

Figura 1: Mapa de localização, em SIRGAS 2000, Zona 25S, da área de estudo situada na praia de Ponta Negra, zona sul de Natal-RN, subdivididas em três sub-áreas (A1, A2 e A3).

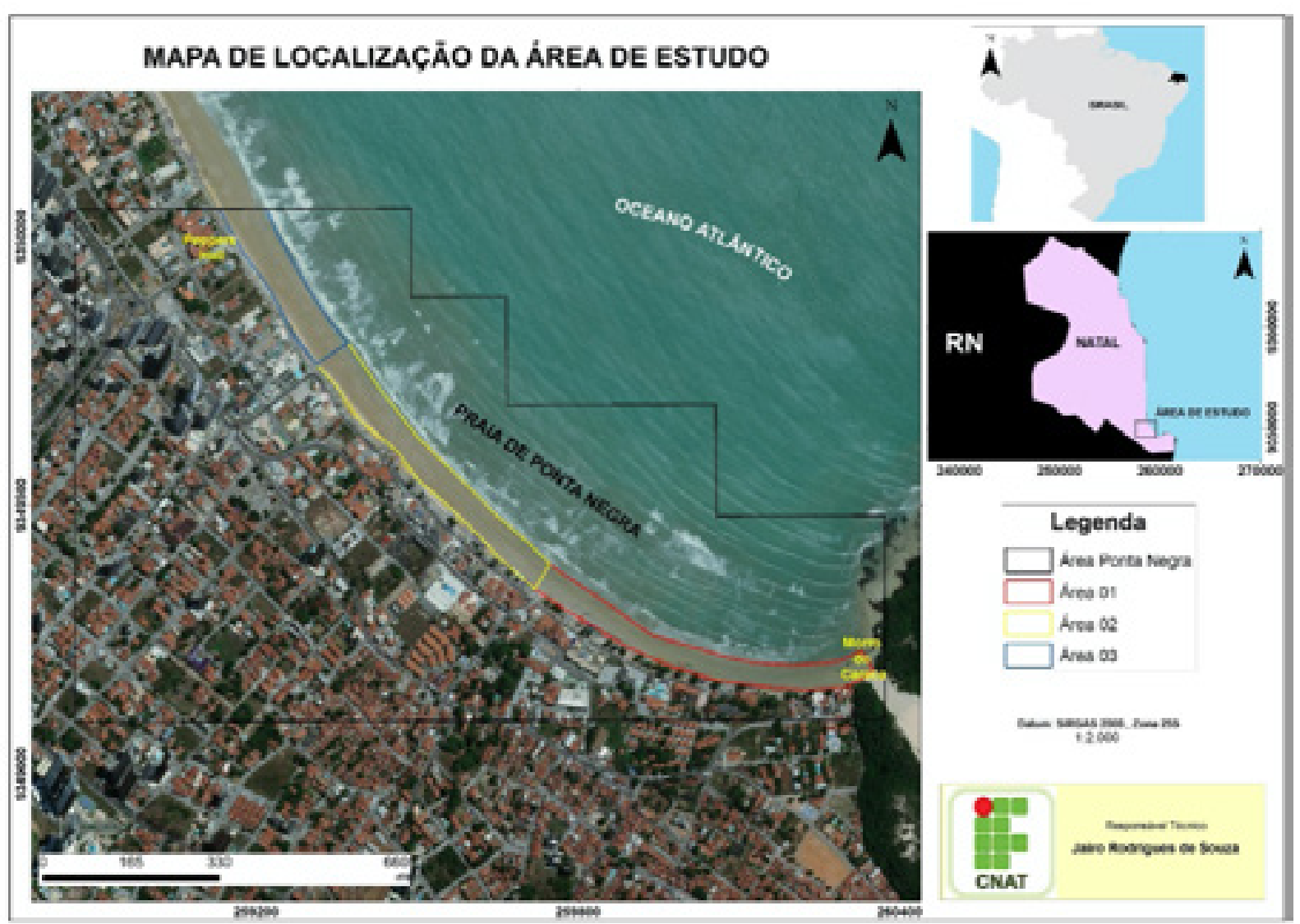

Fonte: Autoria própria (2019)

Os métodos empregados nesses trabalhos foram divididos três etapas: pré-campo, campo e póscampo. Em cada fase, serão realizadas atividades específicas como descritos na figura 02. 
Figura 2: Fluxograma das atividades desenvolvidas no projeto.

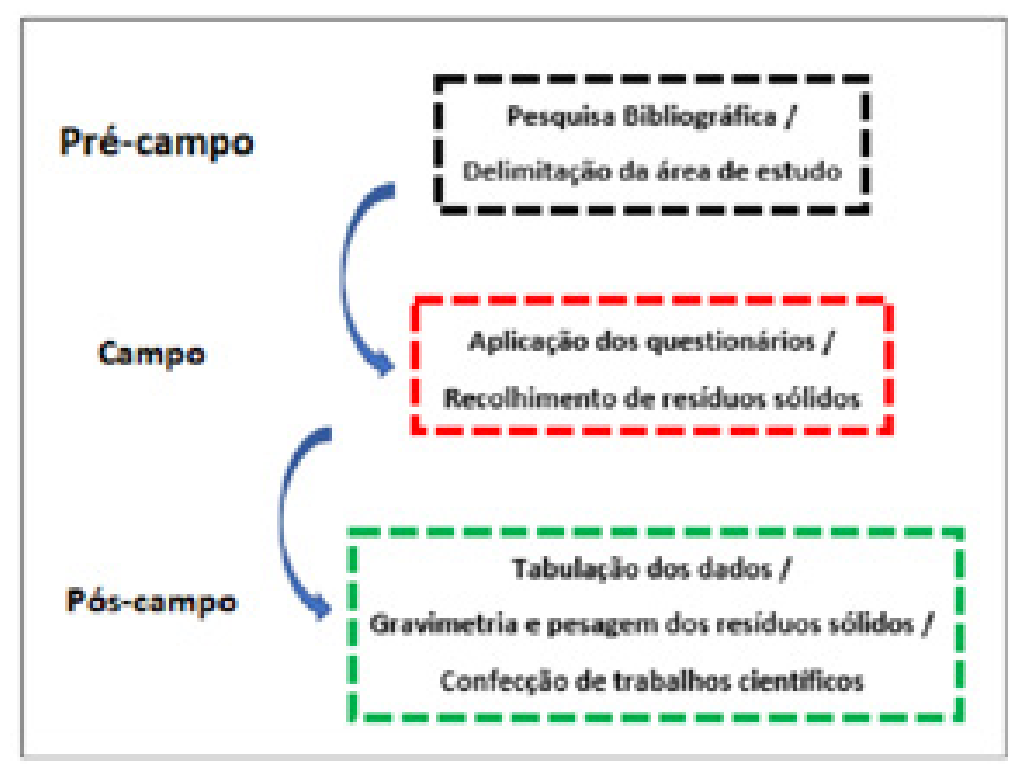

Fonte: Autoria própria (2019).

Esse artigo foi oriundo do projeto de extensão intitulado "Ponta Negra: Menos lixo. Mais saúde", fomentado pelo Instituto Federal de Educação, Ciência e Tecnologia do Rio Grande do Norte Campus Natal-Central (IFRN CNAT). Ele contou com 17 participantes, sendo: 1 coordenador (docente do IFRN CNAT); 16 integrantes compostos por 14 alunos do Curso Técnico Integrado de Controle Ambiental do IFRN CNAT, 01 graduanda da Universidade Potiguar (UnP) e 01 doutoranda da Universidade Federal do Rio Grande do Norte (UFRN).

As atividades foram realizadas durante aos sábados entre os meses de março a agosto de 2018 nos trechos da praia que compreendem uma maior presença dos banhistas, comerciantes e hotéis. Então, a porção da área de estudo foi dividida em três trechos: A1 (Morro do Careca), A2 (zona intermediária) e A3 (área mais distante do Morro do Careca - rua do antigo Peppers Hall). A A1, A2 e A3 contam com comprimentos de 440, 400 e 340 metros de extensão, respectivamente.

Os integrantes foram divididos em três grupos de modo a permanecer e desenvolver as atividades propostas nas áreas estipuladas para coleta de dados (A1, A2 e A3). A obtenção dos resultados se deu a partir da aplicação de questionários semiestruturados de caráter quantitativo (VIEIRA, 1984) com questões acerca da "Idade”, "Sexo", “Renda”, "Zona/região de moradia”, "Frequência de visita”, “Considera Ponta Negra uma praia limpa?”, “Já presenciou alguém jogando resíduos?”, “Já jogou lixo na praia?”, “A quantidade de lixeiras é suficiente?", "Menos lixo significa mais saúde? Por quê?" e "Sugestão para uma praia mais limpa". Cada grupo de alunos recolheu trinta questionários, totalizando 90 ao dia.

A abordagem aos usuários (Figura 03) ocorreu de maneira aleatória e amistosa de acordo com o conselho de ética. No primeiro momento, foi explicado o objetivo do projeto e os termos de consentimento livre e esclarecido. As entrevistas foram realizadas de maneira individual e unitária, mesmo quando abordávamos grupos, visando a não interferência nas respostas. Além da aplicação dos questionários, foram realizadas conversas informais que tinham por prioridade a conscientização 
ambiental dos banhistas, permitindo a reflexão acerca da temática proposta. Em nenhum momento, os participantes foram identificados pelo nome.

Figura 3: Grupos de discentes realizando as entrevistas $(a, b)$ e recolhendo resíduos sólidos (c, d) nas subáreas.
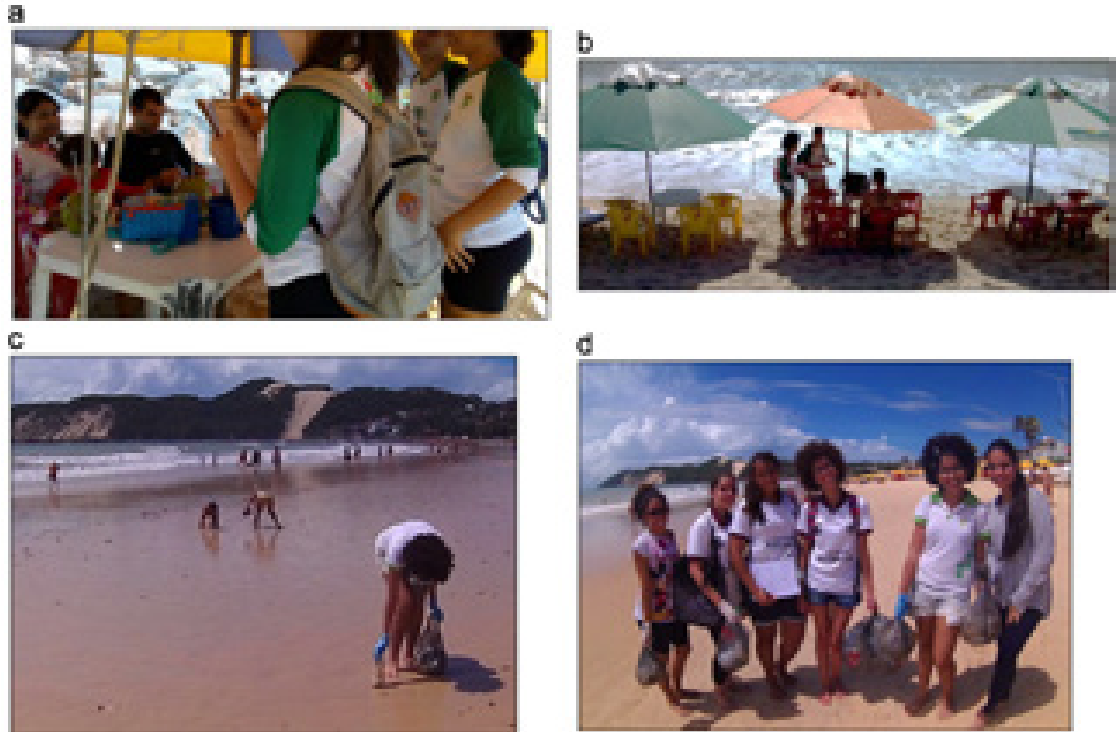

Fonte: Autoria própria (2019).

Adicionalmente, foram coletados resíduos sólidos (Figura 03) ao longo de todas as áreas para separação, pesagem e destino final adequado. 0 intuito dessas coletas era conscientizar os frequentadores da praia, por meio da visualização direta, além deixar o meio ambiente mais limpo. Por fim, todos os questionários, numa quantidade de 974 , foram digitalizados e as respostas de todas ais perguntas tabuladas em planilhas de Excel $\AA^{\circledR}$, e posteriormente, expressos sob a forma de estatística descritiva simples (BUSSAB; MORETTIN, 2003).

\section{RESULTADOS E DISCUSSÕES}

Somente de perto, foi possível observar com afinco a opinião das pessoas e suas impressões. Neste trabalho, conseguiu-se, por meio de diálogos, perceber a qualidade e a funcionalidade da Educação Ambiental em termos locais. Através das perguntas aplicadas nos questionários tornou-se capaz induzir uma inconsciente reflexão sobre estes tópicos ao mesmo tempo que se entendeu o raciocínio dos frequentadores.

Os banhistas que estavam indo pela primeira vez sempre apresentavam uma visão otimista da praia. Muitos deles a compararam com outros cenários do país como, por exemplo, a de Copacabana (Rio de Janeiro-RJ), Iracema (Fortaleza-CE) e dentre outras, no qual em meio a essa comparação Ponta Negra se destacava no quesito limpeza. Já as pessoas que a frequentam sempre não a consideram limpa, mesmo sendo a mais limpa da cidade (Figura 04). A presença de esgotos clandestinos, ratos, resto de pescas e mortalidade de animais marinhos influencia nessa visão negativa. 
Figura 4: Gráficos com a respostas dos entrevistados com relação se (a) "você acha a praia limpa" ou (b) "quantidade de lixeiras é adequada? ". Nota-se que há um paradoxo, pois 70\% acham a praia limpa, mas $87,5 \%$ dizem que não existe lixeiras suficientes.

a

VOCE CONSIDERA A PRAIA LIMPA

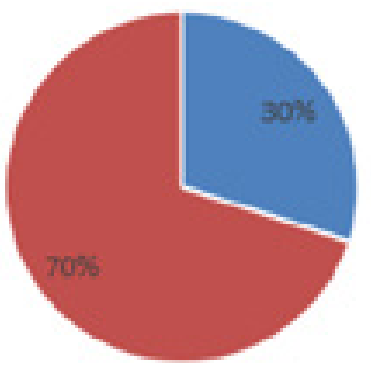

- NLOO . SIN b

\section{QUANTIDADE DE LIXEIRAS É ADEQUADA?}

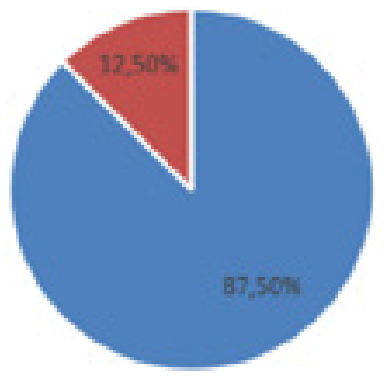

- Nho - $\sin$

Fonte: Autoria própria (2019).

Esse baixo número de lixeiras se deve a indiferença do poder público acerca do bem-estar humano e da biodiversidade, pois na faixa de areia são disponibilizados "latões" que além de serem insuficientes, são provenientes dos donos das barracas. No entanto, as lixeiras disponíveis na praia ficam todas nas calçadas, sendo de difícil acesso e em pouca quantidade.

Quanto à frequência de se presenciar pessoas jogando lixo na praia (Figura 05), a maioria disse que sempre vê, entretanto, com menos frequência que em outras praias de Natal, mas ainda assim é possível observar, diariamente, essa atitude indevida de algumas pessoas. A grande maioria não assumiu que descarta frequentemente resíduos de forma inadequada, disseram ter a atitude de juntar o seu lixo e depositar nas lixeiras que ficam dispostas no calçadão ou até mesmo jogar em casa. Os que assumiram disseram ser poucas às vezes de tal ação e em decorrência da falta de recipientes.

Figura 5: Gráficos com as respostas dos entrevistados com relação se (a) "quantas vezes você jogou lixo no chão" ou (b) "já presenciou alguém jogando lixo na praia".

a

\section{QUANTAS VEZES VOCÊ JOGOU LXXO NO CHÄO}

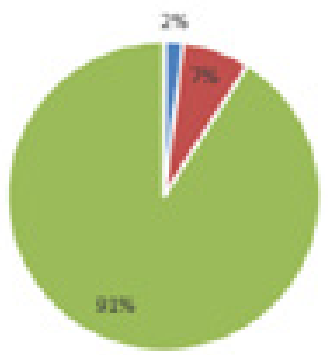

- scmper - POUCes a Nunca b

PRESENCIOU ALGUÉM JOGANDO LIXO NA PRAIA?

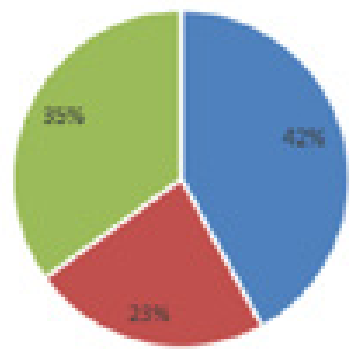

- sempre roucas n nunca

Fonte: Alves et al., (2018) 
Com visitas semanais, foi possível observar de perto a realidade da praia de Ponta Negra, que é um ponto de grande colaboração econômica para a cidade de Natal, e, portanto, necessita de um cuidado maior oriundo dos poderes públicos. É necessária uma maior intervenção para algumas necessidades básicas como, por exemplo, adicionar mais recipientes para coleta de resíduos sólidos na areia da praia, pois praia limpa significa mais saúde, de acordo com a resposta dos entrevistados (Figura 06).

Figura 6: Gráficos com as respostas das pessoas com relação à pergunta "Menos lixo significa mais saúde? " em cada uma das três áreas de atuação do projeto de extensão

Menos lixo significa mais saúde?

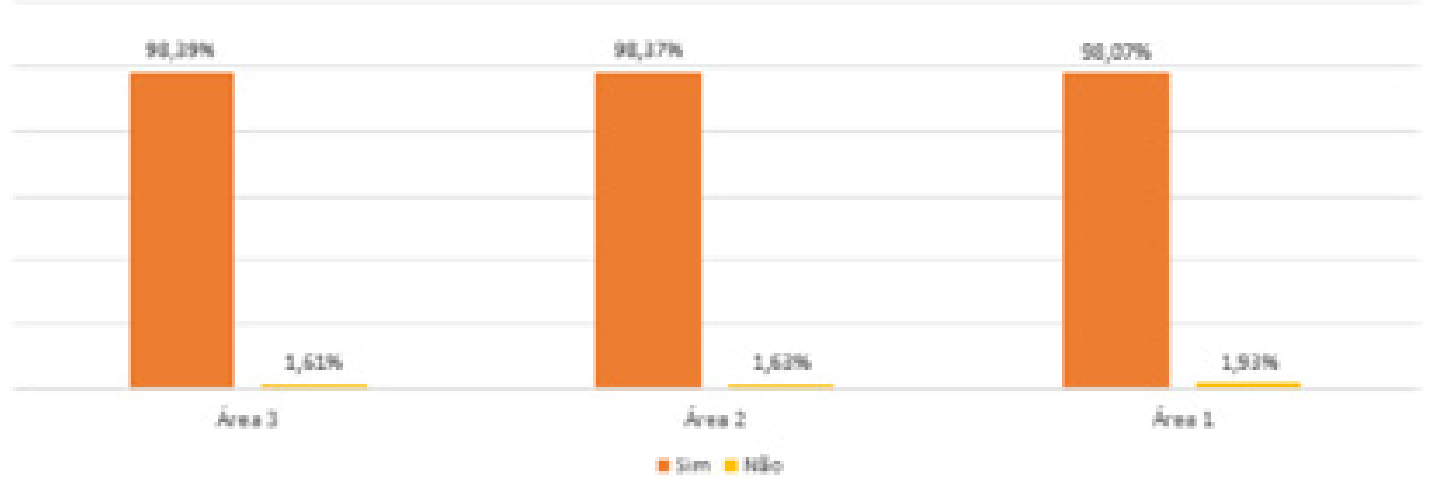

Fonte: Alves et al., (2018)

As pessoas devem ter consciência dos malefícios causados pelos resíduos sólidos despejados de maneira incorreta no ecossistema, e essa conscientização se dá, principalmente, pela educação ambiental. Por mais que essa educação venha conquistando mais espaço dentro da sociedade, a população ainda não tomou consciência do dever que é cuidar do meio ambiente (CARVALHO, 2001). Os entrevistados citaram que com a educação ambiental é possível reduzir vários impactos ambientais provenientes do lançamento inadequado de resíduos, conforme consta no quadro 1.

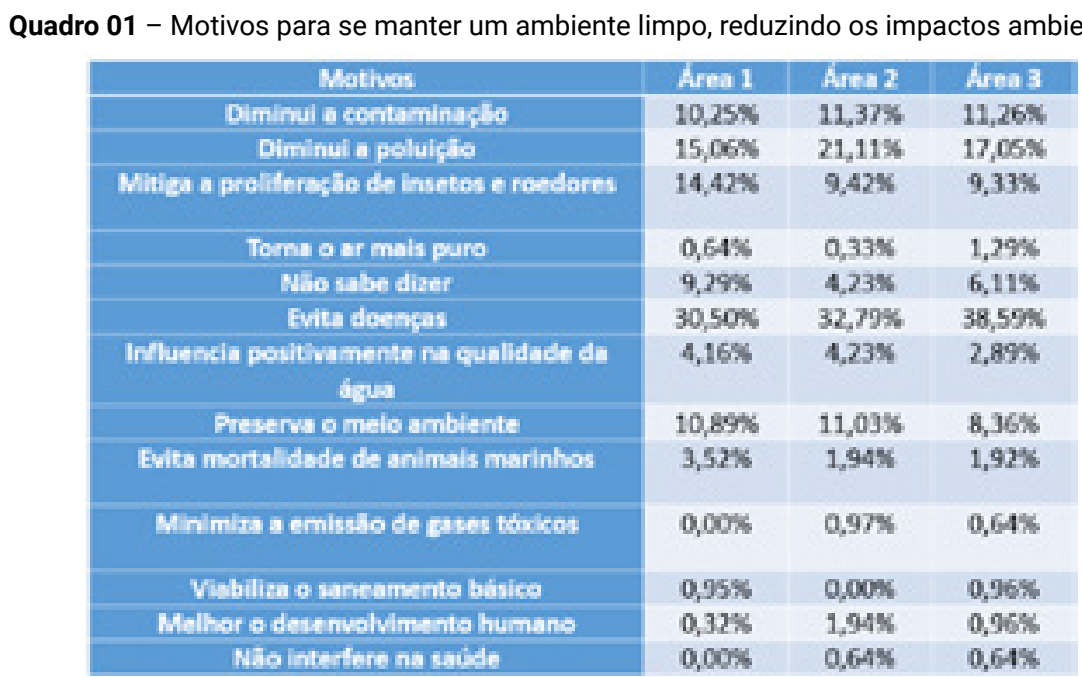

Fonte: Alves et al., (2018). 
Essa questão remete a sustentabilidade, pois segundo o Relatório de Brundtland (1987), sustentabilidade é "suprir as necessidades da geração presente sem afetar a habilidade das gerações futuras de suprir as suas", logo é preciso utilizar esses espaços naturais pensando no meio ambiente como um todo. Esse pensamento é fundamental para aplicação na zona urbana, em especial por se ter uma orla costeira com uma grande dimensão, desde o Morro do Careca até o início da Via Costeira, que se trata de um lugar natural e ao seu redor é totalmente urbanizado, o qual corrobora na geração de impactos ambientais que podem ser remediados com atitudes sustentáveis.

Durante a prática do projeto, também foram realizadas diversas entrevistas com os mercadores da praia de Ponta Negra, sendo essencial para compreender a perspectiva comercial local. Diante disso, muitos afirmaram que é preciso que haja uma cobrança maior sobre turistas e banhistas com a finalidade de manter o ambiente limpo, principalmente sobre aqueles que não possuem o sentimento de responsabilidade diante do ecossistema. Nesse aspecto, é visto que não há cumprimento do art. 225 da Constituição da República Federativa do Brasil, que afirma:

Todos têm direito ao meio ambiente ecologicamente equilibrado, bem de uso comum do povo e essencial à sadia qualidade de vida, impondo-se ao poder público e à coletividade o dever de defendê-lo e preservá-lo para as presentes e futuras gerações (CF, 1988, p.13).

Ademais, ainda abordando sobre o art. 225 da Constituição Federal de 1988, os comerciantes de Ponta Negra afirmaram que, além da maior exigência de responsabilidade por parte dos banhistas e turistas, é preciso que o poder público também assuma o dever de preservar e defender a praia. A partir desses impasses, muitos vendedores sugeriram que haja mais projetos e programas com a temática de educação ambiental, argumentando sobre a necessidade de maior proteção. Essa ideia é posta por Martins e Nishijima (2010), afirmando que a educação ambiental é ferramenta para a preservação de espécies, de ecossistemas e de ambientes naturais.

Freire (1996) corrobora com essa visão, ou seja, declarando que a educação ambiental é de importância inegável sobre o contexto ecológico, social e econômico de uma sociedade, uma vez que as condições materiais em que e sob que vive a sociedade lhe condicionam a compreensão do próprio mundo, sua capacidade de aprender, de responder aos desafios. Assim,

[...] a educação ambiental vai além da discussão sobre os desequilíbrios ambientais, caracterizando a necessidade de se considerar posturas humanas inadequadas, através do investimento na 'reeducação dos sentidos', visando atender os desajustes de uma cultura historicamente situada. (Almeida, 2007, p. 271 apud MELLO, 2013, p. 6).

Nesse aspecto, entende-se que a importância de projetos e programas relacionados ao meio ambiente está relacionada ao fato de poderem intervir na formação de uma sociedade, "reeducando os sentidos", como é apontado pelos frequentadores da praia. 


\section{CONSIDERAÇÕES FINAIS}

Portanto, por mais que os frequentadores considerem a praia de Ponta Negra um ambiente limpo se comparado a outros, todavia muitos apontam que esse ambiente poderia ser melhor cuidado, tendo em vista algumas situações observadas ao longo da orla. Deve-se haver mais iniciativa por parte do poder público que deve realizar uma melhor distribuição de lixeiras na faixa de areia e dos banhistas para contribuírem de modo a não arremessar resíduos sólidos na costa.

Para obter efetividade no tocante aos problemas de gerenciamento dos resíduos sólidos nos arredores da praia, entendemos que é necessária uma parceria mais efetiva entre os civis e a administração pública para que juntos possamos construir uma sociedade sustentável. Assim, é fundamental o papel da educação ambiental, pois a mesma irá conscientizar a população dos impasses da má gestão dos resíduos, e com campanhas de conscientização teremos o nosso cartão postal sempre preservado.

É importante ressaltar que a visão dos comerciantes é de extrema relevância para a compreensão da educação ambiental e do meio ambiente na praia de Ponta Negra, uma vez que são essenciais na intermediação da relação humano-natureza. Dessa forma, através dos relatos dos vendedores, percebeu-se que há negligência por parte da sociedade no geral, sendo necessário mais programas e projetos associados ao meio ambiente.

\section{REFERÊNCIAS}

1. AIRES, J. D.; PEQUENO, E. A.; FORTES, L. A relação entre turistas estrangeiros e residentes: o caso de Ponta Negra - Natal/RN. Revista Hospitalidade, v. 7, n. 2, 2010.

2. ARAÚJO, M. C. B.; SANTIAGO, A. S.; SOARES, S. P. AS DUAS FACES DE UM CARTÃO POSTAL: A PRAIA DE PONTA NEGRA (NATAL-RN), SOB A ÓTICA DE SEUS USUÁRIOS. In: XIII Congresso da Associação Brasileira de Estudos do Quaternário (ABEQUA), 2011, Armação dos Búzios - RJ. Anais do Congresso da Associação Brasileira de Estudos do Quaternário.

3. BENJAMIN, A. H. V. Responsabilidade civil pelo dano ambiental. Revista de direito ambiental, v. 3, n. 9, 1998.

4. BESEN, G. R. et al. Resíduos sólidos: vulnerabilidades e perspectivas. In: SALDIVA P. et al. Meio ambiente e saúde: o desafio das metrópoles. São Paulo: Ex-Libris, 2010.

5. BISPO, C. S. Gerenciamento de resíduos sólidos recicláveis: estudo de caso das cooperativas do município de Natal/RN. Natal, 2013. 243 p. Dissertação de Mestrado. Universidade Federal do Rio Grande do Norte, 2013.

6. BRASIL, Artigo 14 parágrafo $1^{\circ}$ da Lei 6.938 de 1981 da Constituição Federal. Disponível em: $\quad$ <http://www.iap.pr.gov.br/arquivos/File/Legislacao_ambiental/Legislacao_federal/LEIS/LEI_ FEDERAL_6938\%20.pdf>. Acesso em: 14 jul. de 2018.

7. BRASIL, Artigo-lei $\mathrm{n}^{\circ} 255$ da Constituição Federal de 1988. Disponível em: $\quad$ <http://alerjln1.alerj.rj.gov.br/constfed.nsf/16adba33b2e5 
149e032568f60071600f/62e3ee4d23ca92ca0325656200708dde?OpenDocument>. Acesso em: 14 jul. de 2018.

8. BRUNDTLAND, G. H. (Org.) Nosso futuro comum. Rio de Janeiro: FGV, 1987.

9. BUSSAB, W. O. e MORETTIN, P. A. Estatística Básica. São Paulo: Editora Saraiva, 2003.

10. CARDOZO, C. G.; SILVA, L. O. S. A importância do relacionamento interpessoal no ambiente de trabalho. Interbio, Dourados, v. 8, n. 2, 2014.

11. CARTA DA TERRA, 1992. Disponível em: <http://www.mma.gov.br/estruturas/agenda21/_ arquivos/carta_terra.pdf>. Acesso em: 14 jul. de 2018.

12. CARVALHO, I. C. M. Qual Educação Ambiental? Elementos para um debate sobre a educação ambiental e extensão rural. Agroecologia e Desenvolvimento Rural Sustentável, v.2, n.2, 2001.

13. FREIRE, P. A pedagogia da autonomia: saberes necessários à prática educativa. 25. ed. São Paulo: Paz e Terra, 1996.

14. MARTINS, L. A. R.; NISHIJIMA, T. Preservação ambiental e qualidade de vida em comunidades quilombolas, Revista Eletrônica em Gestão, Educação e Tecnologia Ambiental REGET-CT/UFSM, Santa Maria, v.1, n. 1, 2010.

15. MARX, K. O Capital - livro I. 2. ed. São Paulo: Boitempo Editorial, 2011.

16. MELLO, André da Silva. Lazer e educação ambiental: relato de experiências na formação inicial em educação física. Licere, Belo Horizonte, v.16, n.2, 2013.

17. OLIVEIRA, H. C.; SANTOS, J. S. P.; CRUZ, E. F. C. O mundo do trabalho: concepções e historicidade. In: Jornada Internacional de Políticas Públicas - Questão social e desenvolvimento no século XXI, 3, 2007, São Luís. Anais eletrônicos... São Luís: UFMA, 2007.

18. PÁDUA, J. A. (Org.) Ecologia e Política no Brasil, espaço e tempo. Rio de Janeiro: IUPERJ, 1987.

19. PEREIRA, A. Q. Das cidades às metrópoles litorâneas: o papel da vilegiatura marítima moderna no Nordeste do Brasil. Geousp (USP), n. 31, 2012.

20. ROOS, A.; BECKER, E. L. S. Educação ambiental e sustentabilidade, Revista Eletrônica em Gestão, Educação e Tecnologia Ambiental REGET/UFSM, Santa Maria, v. 5, n. 5, 2012.

21. SUGUIO, K. Tópicos de geociências para o desenvolvimento sustentável: as regiões litorâneas. Boletim Geologia USP: Série Didática, v. 2, n. 1, 2003.

22. VIEIRA, Sonia. Metodologia científica. São Paulo: Editora da Unicamp, Sarvier, 1984. 